\title{
Barriers to Insurance as a Flood Risk Management Tool: Evidence from a Survey of Property Owners
}

\author{
Jason Thistlethwaite ${ }^{1} \cdot$ Daniel Henstra $^{2} \cdot$ Craig Brown $^{3} \cdot$ Daniel Scott $^{4}$
}

Published online: 4 May 2020

(C) The Author(s) 2020

\begin{abstract}
By using risk-adjusted price signals to transfer responsibility for property-level flood protection and recovery from governments to property owners, flood insurance represents a key tenet of the flood risk management (FRM) paradigm. The Government of Canada has worked with insurers to introduce flood insurance for the first time as a part of a broader shift towards FRM to limit the growing costs of flooding. The viability of flood insurance in Canada, however, has been questioned by research that disputes the utility of purchasing coverage by property owners. This study tested this assumption by drawing on public opinion survey data to assess factors that influence decisions about the utility of insurance. The findings reveal that Canadians have limited knowledge of flood insurance coverage, exhibit a low willingness-to-pay for both insurance and property-level flood protection measures, and expect governments to shoulder much of the financial burden of flood recovery through disaster assistance.
\end{abstract}

Keywords Flood insurance - Flood risk management $\cdot$ Risk-sharing $\cdot$ Willingness-to-pay

Jason Thistlethwaite

j2thistlethwaite@uwaterloo.ca

1 School of Environment, Enterprise and Development, University of Waterloo, Waterloo, ON N2L 3G1, Canada

2 Department of Political Science, University of Waterloo, Waterloo, ON N2L 3G1, Canada

3 Climate Change and Health Adaptation Planning, Vancouver Coastal Health, Vancouver, BC V5Z 4C2, Canada

4 Department of Geography and Environmental Management, University of Waterloo, Waterloo, ON N2L 3G1, Canada

\section{Introduction}

Globally, flooding is the most common and most costly natural hazard (United Nations 2015). In the coming decades the costs associated with flooding are expected to rise as a result of population growth and expansion of economic activities in flood-prone areas, as well as more frequent and severe extreme weather triggered by climate change (Casey 2015; Winsemius et al. 2016). Flood management has traditionally been dominated by governments, typically via expensive structural controls (for example, dykes) that were meant to separate water from people and property. In response to increasing flood losses, however, this approach has received sustained criticism, and there is an emerging embrace of the principles of integrated flood risk management (FRM) (Sayers et al. 2013). Flood risk management is a strategic framework that focusses on reducing the consequences of flooding by sharing responsibility among a wide range of stakeholders, and coordinating and implementing a diversity of strategies designed to reduce risk across scale and sectors (Begum et al. 2007; Klijn et al. 2008; Simonovic 2013). Flood risk management emphasizes both structural and nonstructural approaches to reduce and manage flood risk, and embraces measures across five interrelated domains: prevention (for example, land-use planning), defense (for example, dykes), mitigation (for example, property-level flood protection), preparation (for example, warning systems), and recovery (for example, financial compensation) (Hegger et al. 2016).

Flood insurance is regarded in many countries as an essential nonstructural tool for FRM for three reasons. First, it is a legitimate and efficient means to finance household recovery from flood damages (Sayers et al. 2013, p. 9). Second, insurance premiums that are set based on the risk of loss create a price signal that can deter risky 
choices while stimulating protective behavior, thereby reducing the financial and logistical burden on governments for disaster recovery (Filatova 2014). Finally, flood insurance shares risk and responsibility beyond governments by engaging the private resources of insurers and property owners themselves, which is a key objective of FRM (World Meteorological Organization 2013).

However, flood insurance is vulnerable to two market imperfections: adverse selection and moral hazard. Adverse selection arises when insurers make coverage available as an add-on to existing policies, but offer it only in areas classified as low-risk or, conversely, when only property owners located in high-risk areas purchase coverage (Sandink et al. 2016). In either case, there is a barrier to market penetration - the proportion of the target market that has purchased insurance-which is critical to achieving a broad pool to spread risk across policyholders. The second problem, moral hazard, refers to the risk that insurance coverage could actually increase vulnerability because insured property owners have less incentive to adopt risk-reduction measures based on their expectation of compensation for loss (Hudson et al. 2017).

Furthermore, a viable flood insurance market requires both a supply of affordable coverage as well as sufficient demand from property owners who are willing to relinquish a specified payment (premium) in exchange for the insurer's promise of compensation in the event of flood-related financial loss. To assess the viability of a particular flood insurance market, therefore, it is essential to examine factors that influence consumer decisions to purchase insurance and to adopt behaviors that reduce adverse selection and moral hazard. Unlike other jurisdictions, such as Germany, the Netherlands, and Scotland, there has been little analysis of Canada's flood insurance market, which is in a unique position as the country is promoting the deployment of flood insurance as a key means of transitioning towards risk-based flood management (Botzen and van den Bergh 2012; Seifert et al. 2013; Owusu et al. 2015).

A key question in Canada is whether demand among property owners will be sufficient to make flood insurance viable, in light of significant policy gaps in Canada's broader approach to flood risk management. These gaps include outdated and inaccessible flood maps, insufficient government engagement to encourage individual responsibility, weak resources to motivate the adoption of property-level flood protection, and moral hazard associated with public disaster assistance. To date, no study comprehensively assesses the factors influencing demand for flood insurance in Canada using public opinion data.

This article seeks to address this gap by describing the results of a survey that probed the attitudes and opinions of property owners as a way to gauge the viability of flood insurance in Canada. The article begins by briefly contextualizing Canada's flood insurance market and by discussing the study's approach to assessing its viability from a supply and demand perspective. The third section draws on existing scholarship to identify several factors that influence consumer behavior in insurance markets. The research design and survey methods are then presented, offering details on the sampling strategy and data analysis. The fifth section presents the survey results, organized into several subsections that relate to the influential factors identified in existing literature. The sixth segment discusses how the results align with existing assumptions on the barriers to viable flood insurance in Canada. The article concludes by summing up the main points of the findings and offering some policy considerations.

\section{The Viability of Flood Insurance in Canada}

Although most property insurance policies include coverage for basement flooding caused by sewer backup or broken pipes, until recently Canadians could not buy insurance against overland flooding, which results from water seeping into buildings through windows, doors, and cracks. This is because it was deemed to lack economic viability due to a lack of randomness (that is, we can predict with relative certainty where flooding is more likely to occur) and mutuality (that is, only a minority of all homeowners are exposed to flood risk) (Sandink et al. 2016).

Overland flood insurance first became available to Canadian property owners in 2015 , prompted largely by a series of pressures that followed from a devastating flood in Calgary, Alberta in 2013. First, faced with vocal demands from flood-affected property owners seeking compensation, Canadian insurers sought to mitigate reputational and regulatory risk by paying out about CAD 1.7 billion in claims that should not have qualified for coverage. Second, when considering flood-related losses from previous years that averaged about CAD 1 billion annually, insurers recognized the financial incentive to begin offering flood insurance (Thistlethwaite 2016). Finally, for several years the government of Canada had encouraged insurers to introduce flood insurance as a means to reduce the escalating costs of federal disaster assistance, which were projected to top CAD 670 million in the coming years (PBO 2016).

Flood insurance prices are not regulated by government. Coverage is optional and is typically offered as a standalone endorsement, or is bundled with existing sewer backup coverage in property insurance policies. Property and casualty insurers have used flood models to estimate hazard probability, property exposure, and vulnerability in 
order to determine that coverage is sustainable over time given uncertainty about the potential loss. They have worked with modelers to develop flood risk maps for underwriting coverage while limiting the ambiguity in predicting high-impact, low-probability flood damages. In other words, insurers have fulfilled the "supply-side" requirements of a viable insurance market, by ensuring that flood insurance will be affordable for property owners, while generating enough premiums to cover damages and remain profitable.

However, demand is also critical for a viable flood insurance market. Indeed, as noted by Seifert et al. "a possible obstacle for an adequately functioning flood insurance system is that individuals need to 'play their role' in the system and buy insurance" (Seifert et al. 2013, p. 1691). There is more uncertainty associated with the demand side of flood insurance, because it is contingent on the behavior of consumers, both in purchasing coverage and in adopting risk-reduction measures in response to differentiated premiums. If consumers do not purchase coverage or respond effectively to insurance price signals, market penetration will be insufficient to spread risk across a diverse set of policyholders and there is a higher likelihood of adverse selection and moral hazard.

\section{The Utility of Flood Insurance Purchase}

Consumer demand for insurance is influenced by the perceived utility of purchasing coverage (Lewis and Nickerson 1989). This utility, however, is shaped by a set of other factors that this section explores in the Canadian context. Flood risk perception has been identified as an important factor in shaping the utility of insurance and is defined as the means through which flood hazards, exposure, and vulnerability are observed and internalized. Individuals inform perceptions of flood risk by processing information that helps assign probability to the negative consequences associated with flooding (Wachinger et al. 2013). With respect to insurance, it has been observed that "demand depends upon the perceived likelihood of loss and the size of the conditional loss" (Petrolia et al. 2013, p. 228).

Risk perception is a critical ingredient for avoiding moral hazard and adverse selection, because it (1) influences how much insurance coverage property owners are willing to purchase; and (2) motivates them to take property-level actions to mitigate risk in response to risk-adjusted premiums. Thieken et al. (2007) confirmed this relationship by noting that households with insurance in Germany had higher risk awareness and were more likely to take protective strategies. However, most studies document low risk perception among property owners, because people in flood-prone areas tend to underestimate their risk (Terpstra and Gutteling 2008; Ludy and Kondolf 2012).

Oulahen (2015) describes how a lack of publicly available maps that identify properties exposed and vulnerable to flooding represents a significant policy gap in Canada, leading many property owners to underestimate their flood risk and muting their demand for flood insurance. A recent study confirmed that Canadian flood maps are not sufficient for influencing risk perception: $62 \%$ failed to meet basic criteria deemed necessary for an individual to determine if their property is at risk from flooding (Henstra et al. 2019). Although some flood maps exist in Canada, they have been developed by provincial governments to inform land use by regulating development in floodplains, and they have been underutilized as a tool for public risk communication (Minano and Peddle 2018). Flood map production in Canada is fragmented-multiple levels of government produce maps for different purposes-and most are outdated, with a median age of 18 years (MMM Group Limited 2014).

In addition to risk perception, the decision to purchase flood insurance is also affected by belief in the effectiveness of property-level flood protection (PLFP) measures (Lewis and Nickerson 1989). Specifically, adoption and willingness-to-pay for PLFP measures limit adverse selection and moral hazard that constrain the availability and affordability of insurance. Adoption of PLFP mechanisms by property owners reduces risk and improves an insurer's capacity to expand the risk pool by including policyholders beyond areas of concentrated risk. Similarly, a high uptake rate of PLFP measures among property owners indicates a lower moral hazard, because there is evidence that they respond to the price signal of risk-adjusted premiums by investing in mitigation.

The utility of investing in PLFP is linked with an individual's "coping appraisal" or their access to resources, time, knowledge, and social supports that feed into a belief that taking action to reduce flood risk will yield benefits (Birkholz et al. 2014). To achieve this behavioral change, many jurisdictions have created and funded initiatives that promote nonstructural flood mitigation by engaging property owners in dialogue about local flood risk, the implications of insurance availability, and resources to support PLFP measures (Affeltranger 2001). These initiatives address key motivators for behavioral change, including trust in FRM authorities, a belief in the efficacy of protective actions, the availability of resources, and a sense of personal ownership in FRM (Parker et al. 2009). Local authorities are the primary actors responsible for this form of stakeholder engagement on flood risk in Canada, but recent research confirms outreach has a narrow focus on information sharing through open houses, social media, and 
workshops and rarely engages the public directly (Henstra and Thistlethwaite 2017).

This gap in flood risk engagement is evident in ongoing confusion and lack of knowledge about the role of insurance (Thistlethwaite 2016). If property owners are confused about their coverage, they may forgo purchasing insurance under the assumption that their existing policy is adequate. Awareness of insurance coverage has received some attention in Canada. For example, based on a survey of 1500 Canadians, Square One Insurance Services (2016) found that $65 \%$ of Canadians incorrectly believed that overland flood coverage was already included in their home insurance policy. Similarly, in a 2004 survey of 2100 homeowners, Sandink et al. (2010) found that nearly $70 \%$ of respondents believed they were insured for flood damages, when in fact the majority were not.

Although coping appraisal is considered an important precursor to purchasing insurance, research has shown that it needs to be combined with a sense of personal responsibility (Terpstra and Gutteling 2008). This relationship has been confirmed in studies in Scotland, Spain, and Germany, where surveys found that respondents who believed they had responsibility for flood risk and were aware of resources were more likely to take actions that protected their property, such as purchasing insurance (Lara et al. 2010; Owusu et al. 2015; Thieken et al. 2016). Encouraging personal responsibility for flood protection is often difficult, particularly in countries like Canada, where flood recovery has traditionally been financed through government disaster assistance programs (Calamai and Minano 2017). Research on insurance demand consistently shows that the availability of disaster assistance reduces the utility of purchasing coverage (Lewis and Nickerson 1989; Kim and Schlesinger 2005; Botzen and van den Bergh 2012; Bubeck et al. 2013).

In Canada, provinces provide disaster assistance in the event that local flood losses exceed a particular financial threshold (for example, 3\% of municipal own-source revenue) or if they are deemed extraordinary and therefore beyond the fiscal capacity of a local authority (Henstra and Thistlethwaite 2017). If these losses exceed a province's capacity to pay, federal disaster assistance is then made available using a financial threshold defined by costs relative to population size (Public Safety Canada 2017). Although flood damage does not qualify for disaster assistance now that insurance is available, these funds continue to be drawn upon to finance recovery. As of 2016, annual payments totaled CAD 600 million annually, which is a five-fold increase over the annual average of CAD 118 million between 1996 and 2011, and this is largely due to an increase in flood losses (PBO 2016; Canadian Underwriter 2017).
Governments in Canada expect newly-available flood insurance to play a key role in Canada's transition to FRM, but insufficient research attention has been devoted to the viability of the flood insurance market, in light of welldocumented barriers to recognizing its utility among property owners. The next section discusses the methods used in the present study, offering details on the survey design, sampling strategy, and data analysis.

\section{Methods}

Existing scholarship on flood insurance viability typically uses willingness-to-pay (WTP) as a measure of whether or not demand is sufficient to achieve a large enough risk pool to ensure coverage is available and premiums are affordable. For instance, in a survey of Australian homeowners, Lo (2013) found that noninsured respondents were not willing to pay an amount that was sufficient, based on actual reported premiums from insured households. In the Netherlands, Botzen and van den Bergh $(2008,2012)$ found that property owners in high-risk areas were willing to pay a sufficient monthly premium for flood insurance, but that individuals in low-risk areas were not willing to pay a sufficient amount. Seifert et al. (2013) surveyed German homeowners and found that 59\% were not willing to pay anything for flood insurance, and those willing to pay indicated a mean value of only EUR 26 per month.

Research on WTP for flood insurance in Canada is limited, but one recent study in Metro Vancouver-a densely-populated urban area on the west coast that is vulnerable to flooding - found that a slight majority of property owners $(52 \%)$ were willing to pay for insurance, while $48 \%$ reported that they were not interested in flood insurance at any price (Oulahen 2015). Among those willing to pay, $68 \%$ were willing to pay up to CAD 100 annually, 23\% were willing to pay between CAD 100 and 200 , and about $10 \%$ were willing to pay more than CAD 200.

A bilingual, national survey was deployed in the spring of 2016; it contained 57 questions that focused on a range of FRM themes (for example, flood experience, risk perception, responsibility, policy support for FRM). Questions ranged in their approach, using a five-point Likert scale to indicate agreement with statements corresponding to insurance policy scenarios, ranking preferences for WTP for PLFP and insurance, as well as how responsibility should be delegated to different stakeholders in flood risk management and assessments on the uptake of PLFP. Ethics approval was granted for the survey in March 2016 followed by pretesting questions with 10 flood hazard experts and a pilot of 25 property owners. Asking Canadians, a survey research firm, administered the survey, 
using strategic random sampling to ensure national representativeness, including 500 from Atlantic Canada, 500 from Quebec, 400 from Ontario, 300 from Manitoba and Saskatchewan, and 300 from each of Alberta and British Columbia $(N=2300)$.

One of the objectives of the survey was to assess the attitudes and actions of Canadians and risk perceptions of those living in high risk flood areas. As such, the survey pursued respondents in "designated areas" —areas identified through the Flood Damage Reduction Program as "subject to recurrent and severe flooding" (Environment and Climate Change Canada 2013). To identify these respondents, a list of Forward Sorting Areas (FSAs) obtained from Canada Post, a Crown corporation that functions as the country's primary postal operator, was sent to the survey firm. Panel participants were then screened to identify their province of residence and to ensure they lived in a high-risk area.

It is important to note that WTP using contingent evaluation has been criticized as a survey method for evaluating insurance demand (Carson and Groves 2007). Since WTP is based on a hypothetical scenario of insurance purchase, responses may not be accurate with some, for example, over-reporting an acceptable price knowing they do not actually have to pay. Survey designs including choice experiments or using visualizations to frame risk have been identified as tools to mitigate these concerns (Seifert et al. 2013). But to establish a baseline at a national scale, we chose to adopt the contingent evaluation approach that is consistent with the limited existing analysis mentioned above.

\section{Results}

This section presents the results of the study, organized according to the factors noted above that have been found to influence the perceived utility of flood insurance purchase.

\subsection{Willingness-to-Pay}

Respondents were asked to identify the price range at which they would consider purchasing overland flood insurance that covered their house for $100 \%$ of flood damages. Although exact figures vary, recent outreach by Canadian insurers suggests that premiums for the average Canadian household would likely cost between CAD 100 and 200 per year for this type of coverage (CBC News 2017). Results in Table 1 show that only $32 \%$ of respondents are willing to pay premiums of CAD $100+/$ year, and $67 \%$ of participants are not yet willing to pay a sufficient amount. Similarly, when respondents were asked "If
Table 1 Willingness-to-pay of Canadians for flood insurance

How much would you be willing to pay for insurance that $\%$ covered $100 \%$ of flood damages? (Canadian \$)

\begin{tabular}{lr}
\hline $0-50$ & 33 \\
$50-100$ & 34 \\
$100-200$ & 16 \\
$200-300$ & 9 \\
$300-400$ & 3 \\
$400-500$ & 2 \\
More than 500 & 2 \\
\hline
\end{tabular}

home insurance for river/stream/lake/pond flooding were made available in your province would you consider purchasing it?", only $24 \%$ indicated that they would, $50 \%$ reported that they would not, and $26 \%$ were unsure.

This low willingness-to-pay could in part be related to the respondents' ability-to-pay, since property located in high risk areas is sometimes occupied by lower-income residents. Additional analysis confirmed some evidence that ability-to-pay could be a factor influencing WTP. While incomes were not found to be low among respondents relative to the Canadian average (the largest share of respondents earned between CAD 50,000 and 100,000), a positive relationship was found between pre-tax income and WTP $(P<0.0003)$. This finding confirms ability-topay is a factor explaining WTP consistent with existing research (Oulahen 2015; Owusu et al. 2015), but the location of the survey respondents did not influence this relationship.

\subsection{Risk Perception}

Of the $50 \%$ of respondents who reported that they would not buy flood insurance, $89 \%$ gave the reason that their home was not at risk of flooding. This low risk perception was consistent within the wider sample of survey respondents, confirming a barrier to insurance demand. Despite stratifying the sample to focus on high-risk flood areas, only $6 \%$ knew that they lived in a designated flood risk area and only $13 \%$ believed that their property was vulnerable to flooding. The survey also asked about respondents' level of concern about current and future flood risk. While $30 \%$ were slightly concerned and $12 \%$ were somewhat concerned about the current risk of flooding, half of the respondents expressed no concern about existing risk. When asked whether property owners thought flood risk would increase over the next 25 years, $72 \%$ believed risk would remain the same, which is out of step with Canadian research that finds climate change is going to increase flood risk in the future (Cheng et al. 2012a, b). 
Table 2 Adoption rates of PLFP

\begin{tabular}{llll}
\hline Have you completed any of these flood protection measures & Adopted $(\%)$ & Incomplete $(\%)$ & Not sure $(\%)$ \\
\hline Graded property away from house & 56 & 14 & 9 \\
Removed expensive items from basement & 27 & 29 & 5 \\
Weeping tile & 47 & 18 & 14 \\
Backwater valve & 39 & 20 & 18.8 \\
Rain barrels connected to downspouts & 21 & 38 & 7 \\
Elevated electrical/HVAC & 35 & 26 & 6 \\
Sump pump & 29 & 26 & 6 \\
\hline
\end{tabular}

Further analysis on these measures of flood risk perception revealed some uncertainty with the relationship with WTP for insurance. While there is a statistically significant relationship between those who believe their property is vulnerable to flood risk and WTP that exceeds CAD $100(P<0.05)$, no relationship is evident with awareness of living in a high-risk area, nor with concern for current and future risk. Despite this inconsistency, the survey results reveal low levels of flood risk perception, which represent a barrier to recognizing the utility of purchasing flooding insurance.

\subsection{Adoption and Willingness-to-Pay for Property- Level Flood Protection}

To understand awareness of the benefits of flood mitigation at the property level, the survey asked questions about the adoption of PLFP and knowledge of flood insurance. Respondents were asked whether they had adopted 11 common PLFP measures, as well as their willingness to pay for these measures. Uptake of PFLP measures was generally weak, and only one-grading soil away from the home-had been implemented by more than $50 \%$ of respondents. The next highest implementation rates included installation of weeping tile or a foundation drain to move subsurface water into the sewer system or onto permeable above-ground surfaces $(47 \%)$ and removing expensive items from the basement $(27 \%)$. More significant measures such as the installation of a backwater valve (a device that shuts to prevent stormwater from backing up into a home during heavy rain) and a sump pump had been adopted by only $39 \%$ and $29 \%$ of respondents, respectively. There is a statistically significant relationship between the number of PLFP measures adopted and WTP. Respondents who adopted more than three PLFP options were willing to pay more for insurance, whereas those who adopted less than three were less likely to pay $(P<0.05)$.

Willingness-to-pay for PLFP reveals a similar pattern: $74 \%$ of respondents were not willing to pay more than
CAD 1,000 and nearly half (48\%) were not willing to pay more than CAD 500 for a contractor to install protection measures. This WTP is insufficient based on estimates from existing research, which indicate that the cost of flood protection measures is typically considerably higher (Keating et al. 2015; Owusu et al. 2015). For example, installing a backwater valve in an existing Canadian home is estimated to cost between CAD 1000 and 2000 depending on the quality of existing storm laterals and plumbing (Sandink 2013).

Similar to the adoption of PLFP measures, there is a correlation with WTP for insurance. Respondents with a WTP that exceeded CAD 500 for PLFP were more likely to pay more for flood insurance (WTP > CAD 100/month), whereas those with a WTP for PLFP below CAD 500 were less likely to pay for flood insurance (WTP $<$ CAD $100 /$ month $)(P<0.0001)$. This finding is also consistent with existing research in Canada and is likely explained by income: respondents with income that exceeded CAD 50,000 annually were more likely to pay for flood insurance, and those with incomes below this threshold were less likely to pay for insurance $(P<0.05)$ (Oulahen 2015).

Shortcomings are also evident in the way that respondents understand the nature of their existing property insurance coverage. Table 3 demonstrates that there is considerable uncertainty among respondents concerning the types of water damage that are covered under their insurance policy, with roughly half unsure of the eligibility of all items except sewer backup. This lack of insurance knowledge is problematic because property owners who believe they are already insured for overland flooding are unlikely to purchase additional coverage. Part of the problem here appears to be inadequate communication by insurers: among respondents, only $25 \%$ had been informed about the availability of overland flood insurance by their broker or agent. Flood insurance only became available among a few companies in 2016, which could explain some of the uncertainty among brokers and property owners. Confusion over flood insurance and the lack of outreach 
Table 3 Understanding of property insurance coverage

\begin{tabular}{llll}
\hline Does your insurance cover: & Yes $(\%)$ & No $(\%)$ & Not sure $(\%)$ \\
\hline Heavy rain entering windows, doors, or vents & 32 & 18 & 50 \\
River flooding entering windows, doors, or vents & 14 & 37 & 49 \\
Sewer/water backup & 58 & 12 & 30 \\
Coastal storm entering through windows, doors, or vents & 12 & 41 & 48 \\
Ground water through basement walls and floor & 28 & 22 & 50 \\
\hline
\end{tabular}

has been documented in smaller scale studies in Canada (Oulahen 2015; Square One Insurance Services 2016), but this analysis confirms the problem exists at the national level.

\subsection{Responsibility for Flood Management}

A set of survey questions asked respondents to provide their opinion on the division of responsibility between governments and insurers in funding the costs of recovery from flooding. Responses confirmed that there is strong support for government responsibility rather than insurers in funding disaster recovery. Respondents were asked to indicate the proportion of flood damage costs (between 1 and $100 \%$ ) that governments should pay. A strong majority $(80 \%)$ believed that governments should pay for between 50 to $100 \%$ of the total costs generated by flood damage. When asked whether they would purchase insurance if the government no longer provided disaster recovery assistance, $44 \%$ of respondents reported that they would, $35 \%$ were not sure, and $17 \%$ indicated that they would not. These findings suggest that government disaster assistance may constitute a disincentive to purchasing private flood insurance, based on an expectation that losses will be covered. Support for government funded recovery reveals further evidence that Canadians perceive a limited utility for the purchase of flood insurance.

\section{Discussion}

Canadians living in high-risk flood areas generally do not intend to purchase flood insurance, are unwilling to pay the premiums required to add overland flood coverage to their policy, perceive little current and future flood risk, have implemented little property-level mitigation, exhibit limited knowledge of existing insurance coverage, and are confused over the division of responsibility for recovery. Although the statistical relationship between these factors and WTP for insurance is inconsistent, the results suggest that Canadians are uncertain about the utility of purchasing flooding insurance. This uncertainty can be attributed to several existing policy gaps.

The fact that so many property owners living in designated flood risk areas underestimate their flood risk is due in part to a lack of publicly available maps that identify properties exposed and vulnerable to flooding (IBC 2015). Other countries have developed online flood information portals to make mapping information publicly accessible, as evidenced in countries including Australia, Belgium, Germany, the Netherlands, the United States, and the United Kingdom (de Moel et al. 2009). In the U.K., for example, flood risk maps are developed and made public by the Environment Agency (EA), whereby property owners can use their postal code to identify their property's flood risk. Local governments consult with the EA when development is proposed in areas at risk of flooding (DEFRA 2017).

Regular map updates are required to recognize changing risk in response to development or shifting hydrological cycles (European Commission 2007; FEMA 2017). Governments and insurers have coordinated map production in some countries to ensure consistency between public risk information and data used to make coverage decisions. In Germany, for example, governments have established four flood zones, each with different insurance coverage conditions (Sandink et al. 2010). Since these maps are informed by insurers, brokers and property owners enjoy more confidence in determining whether to purchase coverage. A similar coordinated strategy could address the low levels of flood insurance awareness in Canada. Survey results from the 2016 national survey reveal strong public support for these international approaches to flood risk mapping. Almost all respondents (92\%) agreed that flood risk maps should be made publicly available, that provinces should require municipalities to use maps 10 years old or newer $(88 \%)$, and that property sellers in high flood risk areas should be required to disclose the risk to potential buyers $(91 \%)$.

Although flood risk information has been proven to support the intention to purchase flood insurance, a belief that insurance and other measures (for example, PLFP) are effective in reducing risk is also necessary to improve the 
utility of insurance purchase. Other countries have recognized this and have developed national programs to support local engagement efforts. In England, for example, the Pathfinder Program funded local flood wardens who educate community members on risk reduction, resources and programs that support PLFP, and the impact of past floods (Twigger-Ross et al. 2015).

In Canada, a lack of resources from upper-tier governments is a barrier to expanding these programs. A 2016 Auditor General report that reviewed the federal government's spending on disaster management, for instance, revealed that funding for flood mitigation (for example, programs supporting PLFP, mapping, and risk assessment) have not been a priority (OAG 2016). The Government of Canada recently committed CAD 200 million (over 5 years) to the National Disaster Mitigation Program (NDMP) with the objective of improving local, nonstructural risk mitigation, including risk assessments, flood mapping, mitigation planning, and small-scale projects such as flood warning systems and replacing urban flood infrastructure (Government of Canada 2018). However, the program requires local governments to pay $50 \%$ of project costs, which limits the consistency and resources necessary for sufficient institutional capacity at the local level (Shrubsole 2000). Although the funding is being used to support risk mapping and assessment, no funded projects have involved engagement with the public, which is needed to improve coping appraisal and an understanding of how flood insurance yields benefits (Thistlethwaite and Henstra 2017).

Finally, governments must reduce their role in supporting recovery through disaster assistance. Although governments generally recognize that the cost of disaster assistance is unsustainable in light of growing flood losses, they routinely bend to political pressure in the aftermath of major flood events (Wamsley and Schroeder 1996; Calamai and Minano 2017). Moreover, insurance is not affordable in many high-risk areas, despite provincial efforts to signal to property owners that flood-related damage will not be eligible for disaster assistance where flood insurance is available (for example, British Columbia 2016; Manitoba 2017). To expand coverage and limit the deployment of disaster assistance, a recent industry-led proposal endorses a risk pool similar to the Flood Re model adopted in the United Kingdom (IBC 2019). A risk pool approach could address the findings that those with lower incomes are less likely to purchase insurance by subsidizing the price of coverage. The report notes that limiting the availability of disaster assistance is a critical precondition for the scheme's viability, but the federal government has not indicated that such reform is likely, and most provinces oppose such limits, arguing that they cannot afford to absorb additional costs. More broadly, most property owners seem unaware of changes in the insurance market, and high-risk areas where insurance is unavailable will remain dependent on government assistance.

\section{Conclusion}

Flood insurance is considered a critical nonstructural policy tool in effective flood risk management. Risk-adjusted premiums generate price signals that incentivize risk reduction and redistribute risk and responsibility away from governments and individual property owners to a large risk pool. The viability of flood insurance, however, is contingent on a set of precarious conditions. Insurers must be able to predict and price risk at a level that is affordable, sufficient to compensate for potential claims, and risk-adjusted to limit adverse selection and moral hazard. Consumer behavior that supports demand for coverage and responds to risk-price signals is critical for insurers to maintain the balance between affordability and risk-adjustment to manage adverse selection and moral hazard.

Research using public surveys has sought to understand consumer behavior in other countries, but analysis of Canada's emerging insurance market has been scarce. This study addressed this gap by using nationally representative public opinion data to assess perceptions of the utility of purchasing insurance. The findings reveal a low WTP, particularly in high-risk areas where almost all respondents underestimate their flood risk, and a majority still believe governments should pay half of recovery costs. Respondents demonstrated limited willingness-to-pay and weak adoption of property-level flood protection, were unaware of the benefits of flood insurance, and demonstrated confusion over the differences in available coverage, which signal limits in individual coping appraisal, as well as weak knowledge of the benefits of purchasing insurance or taking action to reduce risk.

The findings of this study are consistent with other research on the barriers to viable flood insurance that identify some important preconditions, including accessible flood risk mapping, funding and programming to support local mitigation and adoption of PLFP, and limits on the availability of disaster assistance. The results also justify further research to help identify how these strategies can improve the utility of flood insurance. Alternative methods to determine willingness-to-pay, such as disclosing the level of risk through a visualization (for example, risk ladder, or 3D visualization) or testing different policy scenarios, could refine some of the inconsistencies found in this study and improve the links between utility and different policy interventions. Different flood mapping visualizations and formats could also be tested in small 
controlled experiments to identify whether barriers to insurance demand are mitigated.

This study also confirms an opportunity for Canadian governments to adopt policies that strengthen the consumer demand required for viable flood insurance. In particular, better coordination is needed to assign responsibilities and broaden the portfolio of policy instruments employed in flood management. The current approach relies on local governments to encourage insurance demand by accessing funding for risk maps and stakeholder engagement on a project-by-project basis and underutilizes the resources and capacity of the federal government. This approach contrasts sharply with those of Canada's industrial counterparts, in which the national government plays a key role on coordinating responsibilities between levels of government.

Acknowledgements This research was funded by the Social Sciences and Humanities Research Council of Canada under Grant 430-201500521. The authors thank Truzaar Dordi for his research assistance, as well as Shawna Peddle for her diligent contributions to the survey that inspired this article.

Open Access This article is licensed under a Creative Commons Attribution 4.0 International License, which permits use, sharing, adaptation, distribution and reproduction in any medium or format, as long as you give appropriate credit to the original author(s) and the source, provide a link to the Creative Commons licence, and indicate if changes were made. The images or other third party material in this article are included in the article's Creative Commons licence, unless indicated otherwise in a credit line to the material. If material is not included in the article's Creative Commons licence and your intended use is not permitted by statutory regulation or exceeds the permitted use, you will need to obtain permission directly from the copyright holder. To view a copy of this licence, visit http://creativecommons. org/licenses/by/4.0/.

\section{References}

Affeltranger, B. 2001. Public participation in the design of local strategies for flood mitigation and control. Paris: International Hydrological Programme, UNESCO.

Begum, S., M.J.F. Stive, and J.W. Hall, eds. 2007. Flood risk management in Europe: Innovation in policy and practice. Dordrecht, The Netherlands: Springer Netherlands.

Birkholz, S., M. Muro, P. Jeffrey, and H.M. Smith. 2014. Rethinking the relationship between flood risk perception and flood management. Science of the Total Environment 478(1): 12-20.

Botzen, W.J.W., and J.C.J.M. van den Bergh. 2008. Insurance against climate change and flooding in the Netherlands: Present, future and comparison with other countries. Risk Analysis 28(2): 413-426.

Botzen, W.J.W., and J.C.J.M. van den Bergh. 2012. Risk attitudes to low-probability climate change risks: WTP for flood insurance. Journal of Economic Behavior \& Organization 82(1): 151-166.

British Columbia. Emergency Management. 2016. Disaster Financial Assistance (DFA) and residential flood insurance. Victoria, BC: Government of British Columbia. https://www2.gov.bc.ca/ assets/gov/public-safety-and-emergency-services/emergency- preparedness-response-recovery/embc/dfa/residential_flood_ insurance.pdf. Accessed 15 Dec 2016.

Bubeck, P., W.J.W. Botzen, H. Kreibich, and J.C.J.H. Aerts. 2013. Detailed insights into the influence of flood-coping appraisals on mitigation behaviour. Global Environmental Change 23(5): $1327-1338$.

Calamai, L., and A. Minano. 2017. Emerging trends and future pathways: A commentary on the present state and future of residential flood insurance in Canada. Canadian Water Resources Journal 42(4): 307-314.

Canadian Underwriter. 2017. Severe weather, nat-cats cause record insurable damage in Canada: IBC/CATIQ. Toronto: Canadian Underwriter. https://www.canadianunderwriter.ca/catastrophes/ severe-weather-nat-cats-cause-record-insurable-damage-canadaibccatiq-1004106311/. Accessed 17 Feb 2018.

Carson, R.T., and T. Groves. 2007. Incentive and informational properties of preference questions. Environmental and Resource Economics 37(1): 181-210. https://doi.org/10.1007/s10640-0079124-5.

Casey, M. 2015. Global cost of flooding to increase tenfold by 2030. CBS News. https://www.cbsnews.com/news/global-cost-of-flood ing-to-increase-tenfold-by-2030/. Accessed 17 Jan 2017.

CBC News. 2017. Canadian homeowners in the dark about flood risks, study suggests. https://www.cbc.ca/radio/thecurrent/thecurrent-for-may-5-2017-1.4099475/canadian-homeowners-inthe-dark-about-flood-risks-study-suggests-1.4099513. Accessed 6 May 2017.

Cheng, C.S., Q. Li, G. Li, and H. Auld. 2012a. Climate change and heavy rainfall-related water damage insurance claims and losses in Ontario, Canada. Journal of Water Resource and Protection 4(2): 49-62.

Cheng, C.S., Q. Li, G. Li, and H. Auld. 2012b. Possible impacts of climate change on daily streamflow and extremes at local scale in Ontario, Canada. Part II: Future projection. Atmospheric and Climate Sciences 2: 427-440.

de Moel, H, J. van Alphen, and J.C.J.H. Aerts. 2009. Flood maps in Europe - Methods, availability and use. Natural Hazards and Earth System Sciences 9(2): 289-301.

DEFRA (Department for Environment Food and Rural Affairs). 2017. Flood risk assessment: Local planning authorities. London: DEFRA. https://www.gov.uk/guidance/flood-risk-assessmentlocal-planning-authorities. Accessed 9 Jun 2019.

Environment and Climate Change Canada. 2013. Flood Damage Reduction Program. https://www.ec.gc.ca/eau-water/default. asp?lang=En\&n=0365F5C2-1. Accessed 23 May 2017.

European Commission. 2007. A new EU floods directive - Environment - European Commission. Belgium: European Commission. https://ec.europa.eu/environment/water/flood_risk/. Accessed 20 Jun 2020.

FEMA (Federal Emergency Management Agency). 2017. Map modernization. Washington, DC: FEMA. https://www.fema. gov/map-modernization. Accessed 4 Mar 2020.

Filatova, T. 2014. Market-based instruments for flood risk management: A review of theory, practice and perspectives for climate adaptation policy. Environmental Science \& Policy 37(1): $227-242$.

Government of Canada. 2018. National Disaster Mitigation Program (NDMP). Ottawa: Government of Canada. https://www.public safety.gc.ca/cnt/mrgnc-mngmnt/dsstr-prvntn-mtgtn/ndmp/indexen.aspx. Accessed 10 Jan 2020.

Hegger, D., P.P.J. Driessen, M. Wiering, H.F.M.W. van Rijswick, Z.W. Kundzewicz, P. Matczak, A. Crabbé, G.T. Raadgever, et al. 2016. Toward more flood resilience: Is a diversification of flood risk management strategies the way forward? Ecology and Society 21(4): Article 52. 
Henstra, D., and J. Thistlethwaite. 2017. Climate change, floods, and municipal risk sharing in Canada. IMFG papers on Municipal Finance and Governance, No. 30. Toronto: Institute on Municipal Finance and Governance. https://munkschool.utoronto.ca/ imfg/uploads/373/1917_imfg_no_30_online_final.pdf. Accessed 9 Apr 2020.

Henstra, D., A. Minano, and J. Thistlethwaite. 2019. Communicating disaster risk? An evaluation of the availability and quality of flood maps. Natural Hazards and Earth System Sciences 19(1): 313-323.

Hudson, P., W.J.W. Botzen, J. Czajkowski, and H. Kreibich. 2017. Moral hazard in natural disaster insurance markets: Empirical evidence from Germany and the United States. Land Economics 92(2): 179-208

IBC (Insurance Bureau of Canada). 2015. The financial management of flood risk: An international review of lessons learned from flood management programs in G8 Countries. Toronto, ON: IBC.

IBC (Insurance Bureau of Canada). 2019. Options for managing flood costs of Canada's highest risk residential properties. Toronto, ON: IBC. https://www.ibc.ca/on/resources/studies/options-formanaging-flood-costs-of-canada $\%$ E2\% $80 \% 99$ s-highest-risk-resi dential-properties. Accessed 5 Jan 2020.

Keating, K., P. May, A. Pettit, and R. Pickering. 2015. Cost estimation for household flood resistance and resilience measures - Summary of evidence. London, UK: Environment Agency. https://evidence.environment-agency.gov.uk/FCERM/ Libraries/FCERM_Project_Documents/SC080039_cost_house_ resist_and_resilience.sflb.ashx. Accessed 6 Jan 2020.

Kim, B.J., and H. Schlesinger. 2005. Adverse selection in an insurance market with government-guaranteed subsistence levels. Journal of Risk and Insurance 72(1): 61-75.

Klijn, F., P. Samuels, and A. Van Os. 2008. Towards flood risk management in the EU: State of affairs with examples from various European countries. International Journal of River Basin Management 6(4): 307-321.

Lara, A., D. Saurí, A. Ribas, and D. Pavón. 2010. Social perceptions of floods and flood management in a Mediterranean area (Costa Brava, Spain). Natural Hazards and Earth System Science 10(10): 2081-2091.

Lewis, T., and D. Nickerson. 1989. Self-insurance against natural disasters. Journal of Environmental Economics and Management 16(3): 209-223

Lo, A.Y. 2013. Household preference and financial commitment to flood insurance in South-East Queensland. Australian Economic Review 46(2): 160-175.

Ludy, J., and G. Matt Kondolf. 2012. Flood risk perception in lands 'protected' by 100-year levees. Natural Hazards 61(2): 829-842.

Manitoba. 2017. Disaster financial assistance. Winnipeg, MB: Government of Manitoba. https://www.gov.mb.ca/emo/recover/ home/dfa_home.html. Accessed 7 Jan 2019.

Minano, A., and S. Peddle. 2018. Using flood maps for community flood risk communication. Report prepared for Natural Resources Canada. Waterloo, ON: Partners for Action. https:// uwaterloo.ca/partners-for-action/sites/ca.partners-for-action/ files/uploads/files/using_flood_maps_for_community_flood risk_communication_24jan18_fnl.pdf. Accessed 20 May 2019.

MMM Group Limited. 2014. National floodplain mapping assessment: Final report. Ottawa, ON: Public Safety Canada.

OAG (Office of the Auditor General of Canada). 2016. Report 2 Mitigating the impacts of severe weather. Ottawa, ON: Office of the Auditor General of Canada. https://www.oag-bvg.gc.ca/ internet/English/parl_cesd_201605_02_e_41381.html\#p34. Accessed 15 Jul 2019.

Oulahen, G. 2015. Flood insurance in Canada: Implications for flood management and residential vulnerability to flood hazards. Environmental Management 55(3): 603-615.
Owusu, S., G. Wright, and S. Arthur. 2015. Public attitudes towards flooding and property-level flood protection measures. Natural Hazards 77(2): 1963-1978.

Parker, D.J., S.J. Priest, and S.M. Tapsell. 2009. Understanding and enhancing the public's behavioural response to flood warning information. Meteorological Applications 16(1): 103-114.

PBO (Parliamentary Budget Officer). 2016. Estimate of the average annual cost for disaster financial assistance arrangements due to weather events. Ottawa, ON: Office of the Parliamentary Budget Officer.

Petrolia, D., C. Landry, and K. Coble. 2013. Risk preferences, risk perceptions and flood insurance. Land Economics 89(2): 227-245.

Public Safety Canada. 2017. 2016-2017 evaluation of the disaster financial assistance arrangements. Ottawa, ON: Government of Canada. https://www.publicsafety.gc.ca/cnt/rsrcs/pblctns/vltndsstr-fnncl-ssstnc-2016-17/index-en.aspx\#s42. Accessed 13 Sept 2019.

Sandink, D. 2013. Open to interpretation. Canadian Underwriter (blog), 1 January 2013. https://www.canadianunderwriter.ca/ features/open-to-interpretation/. Accessed 9 Apr 2020.

Sandink, D., P. Kovacs, G. Oulahen, and G. McGillivray. 2010. Making flood insurable for Canadian homeowners: A discussion paper. Toronto, ON: Institute for Catastrophic Loss Reduction \& Swiss Reinsurance Company Ltd. https://www.iclr.org/wpcontent/uploads/PDFS/making-flood-insurable-for-canadianhomeowners.pdf. Accessed 12 Jan 2019.

Sandink, D., P. Kovacs, G. Oulahen, and D. Shrubsole. 2016. Public relief and insurance for residential flood losses in Canada: Current status and commentary. Canadian Water Resources Journal 41(1-2): 220-237.

Sayers, $P$., L. Yuanyuan, G. Galloway, E. Penning-Rowsell, S. Fuxin, W. Kang, C. Yiwei, T. Le Quesne. 2013. Flood risk management: A strategic approach. Paris: UNESCO.

Seifert, I., W.J.W. Botzen, H. Kreibich, and J.C.J. Aerts. 2013. Influence of flood risk characteristics on flood insurance demand: A comparison between Germany and the Netherlands. Natural Hazards and Earth System Sciences 13(7): 1691-1705.

Shrubsole, D. 2000. Flood management in Canada at the crossroads. Environmental Hazards 2(2): 63-75.

Simonovic, S.P. 2013. Floods in a changing climate: Risk management. Cambridge: Cambridge University Press.

Square One Insurance Services. 2016. Square One finds $65 \%$ of Canadians wrongfully believe that home insurance protects against flood damage. Vancouver: Square One Insurance Services. https://www.squareoneinsurance.com/inland-flood-pro tection. Accessed12 Jul 2019.

Terpstra, T., and J.M. Gutteling. 2008. Households' perceived responsibilities in flood risk management in The Netherlands. International Journal of Water Resources Development 24(4): $555-565$.

Thieken, A.H., H. Kreibich, M. Müller, and B. Merz. 2007. Coping with floods: Preparedness, response and recovery of floodaffected residents in Germany in 2002. Hydrological Sciences Journal 52(5): 1016-1037.

Thieken, A., S. Kienzler, H. Kreibich, C. Kuhlicke, M. Kunz, B. Mühr, M. Müller, et al. 2016. Review of the flood risk management system in Germany after the major flood in 2013. Ecology and Society 21(2): Article 51.

Thistlethwaite, J. 2016. The emergence of flood insurance in Canada: Navigating institutional uncertainty. Risk Analysis 37(4): 744-755.

Thistlethwaite, J., and D. Henstra. 2017. Protection for those who need it most: Sustainable property insurance in high-risk areas. Waterloo, ON: Centre for International Governance Innovation. https://www.cigionline.org/publications/protection-those-who- 
need-it-most-sustainable-property-insurance-high-risk-areas. Accessed 18 Mar 2019.

Twigger-Ross, C., P. Orr, K. Brooks, R. Sadaukis, H. Deeming, J. Fielding, T. Harres, R. Johnston, et al. 2015. Flood resilience community pathfinder evaluation: Final evaluation report. London, UK: Department for Environment Food and Rural Affairs.

United Nations. 2015. The human cost of weather-related disasters 1995-2015. Geneva: United Nations Office for Disaster Risk Reduction.

Wachinger, G., O. Renn, C. Begg, and C. Kuhlicke. 2013. The risk perception paradox-Implications for governance and communication of natural hazards. Risk Analysis 33(6): 1049-1065.
Wamsley, G.L., and A.D. Schroeder. 1996. Escalating in a quagmire: The changing dynamics of the emergency management policy subsystem. Public Administration Review 56(3): 235-246.

Winsemius, H.C., J.C.J.H. Aerts, L.P.H. van Beek, M.F.P. Bierkens, A. Bouwman, B. Jongman, J.C.J. Kwadijk, W. Ligtvoet, et al. 2016. Global drivers of future river flood risk. Nature Climate Change 6(4): 381-385.

World Meteorological Organization. 2013. Risk sharing in flood management. Geneva: World Meteorological Organization. 